\title{
Fabrication of $\beta$-Silicon Carbide Nanowires from Carbon Powder and Silicon Wafer
}

\author{
Majid S. Al-Ruqeishi*, Tariq Mohiuddin \\ Department of Physics, College of Science, Sultan Qaboos University, P.O. Box 36 \\ P.C. 123, Al-Khoudh, Sultanate of Oman
}

(Received 09 February 2016; published online 21 June 2016)

\begin{abstract}
$\beta$-SiCNWs were synthesized by simple carbo-thermal process using silicon wafer and carbon powder only. The obtained $\beta$-SiCNWs were short and thick with random distribution over Si wafer surface when rapid heating rate is applied. While $\beta$-SiCNWs fabricated under low heating rate are $57.0 \pm 3.0 \mathrm{~nm}$ in average diameter and few millimeters in length. An ambient Ar gas flow rates were found to be critical in the growth yield of resultant $\beta$-SiC nanowires. XRD diffraction patterns and FTIR spectrum reveals the composition structure of theses wires.
\end{abstract}

Keywords: Carbo-thermal technique, SiC Nanowires, Nano-Optics.

\section{INTRODUCTION}

Recently, one-dimensional (1D) nanostructures, such as tubes, wires, belts and rings, have stimulated intensive research interesting, because of their great potential for understanding basic issues about dimensionalities and space confined transport phenomena $[1,2]$. As a wide band gap semiconducting material, silicon carbide ( $\mathrm{SiC})$ exhibits many excellent properties for high temperature, high frequency and high power applications [3]. SiC 1D nanostructures can be used in field emission display, nano-sensors and electro-devices [4-6]. Thus, in the last few years, much effort has been made to the synthesis of $1 \mathrm{D} \mathrm{SiC}$ nanostructures. Recently, many techniques were demonstrated, including CNT-confined growth [7], chemical vapor deposition (CVD) [8-10], carbo-thermal [4, $11,12]$, polymeric precursor pyrolysis method [13], laser ablation [14] and arc discharge [15]. However, most of these synthetic approaches involved complex processes and manipulations. Catalytic growth methods uses different materials like Ni [16] at $T=1000^{\circ} \mathrm{C}, \mathrm{Fe}$ at $T=1250{ }^{\circ} \mathrm{C}$ [17]. The usage of metal catalyst for nanowires growth makes it difficult to remove the resident catalyst after the synthetic process finished. On the other hand, it has been proposed that non-catalytic carbo-thermal technique can be used to fabricate centimeterscale ultra-long $\mathrm{SiC}$ nanowires at $T=1250-1300^{\circ} \mathrm{C}$ and longer wires were founded when the carrier flowing gas kept at its lower value [18]. Latterly, a simulation study of $\mathrm{Z}$. Li et al. [19] found that longer deposition time, i.e. less flow rate, increases the yield of grown SiCNWs. We reported in our previous study [20] the growth of $\beta$-SiC nanowires but without studying the effects of the rapid heating rate and ambient gas flowrates on the morphology of the resultant nanowires. Therefore, In this article, a direct carbo-thermal technique was utilized to synthesize ultra-long $\beta$-SiC nanowires at $T=1200^{\circ} \mathrm{C}$ without catalyst as well as studying the effects of rapid heating and Ar flow rates on the yield of grown $\beta$-SiC nanowires. The detailed characterizations on the resulting nanostructures were carried out by field-emission scanning electron microscopy (FESEM), energy- dispersed X-ray spectroscopy (EDX), X-ray diffraction (XRD) and fourier transform infrared spectroscopy (FTIR).

\section{EXPERIMENT SETUP}

A $(2 \times 1) \mathrm{cm}$ Si (100) substrates with a resistivity of $5.15 \Omega \cdot \mathrm{cm}^{-2}$ were ultrasonically cleaned in acetone for 5 minutes. Then the substrates were dried in air. After that, the substrate was loaded into the middle of a 2.2 cm-inner diameter quartz tube (Lianyungang Lanno Quartz Co., Ltd.) placed at the center of a horizontal tube furnace (Lindberg/Blue M, STF54233c). Carbon powder $(2 \mathrm{~g})$ on a porcelain boat was mounted $2 \mathrm{~cm}$ before the silicon substrate as shown in Fig. 1. The argon $(99.999 \%)$ gas was then flushed inside the quartz tube and kept at 10 standard cubic centimeters per minute $(\mathrm{sccm})$ or as required. The temperature was then raised up to $1200{ }^{\circ} \mathrm{C}$ at a heating rate of $1.2{ }^{\circ} \mathrm{C} / \mathrm{s}$ and kept unchanged.

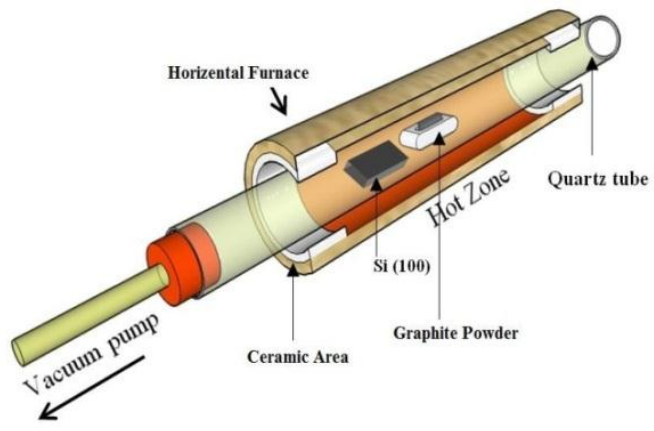

Fig. 1 - A schematic diagram of charbo-thermal experiment setup for $\beta$-SiC nanowires fabrication system

\section{RESULT AND DISCUSSIONS}

\subsection{Effect of Rapid Heating Rate on the Growth of $\beta$-SiCNWs}

In this experiment, the furnace was first heated up to $1200{ }^{\circ} \mathrm{C}$ and a carbon boat and prepared substrates were loaded directly into the middle of the furnace. The substrate was placed $2 \mathrm{~cm}$ apart from the carbon boat. After that, the system was vacuumed and followed by Ar gas for one hour. After cooling down to room temperature, samples were taken for characterization. The obtained $\beta$-SiC nanowires were distributed in bundles, randomly over the substrate surface and the nanowires are not aligned as can be seen in Fig. 2 (a-c). EDX spectrum in Fig. 2(d) reveals that nanowires in Fig. 2(c)

\footnotetext{
*majidruq@squ.edu.om
} 
consist of carbon, oxygen and silicon with different weight percentages. In Fig. 2(c) the crowded wires are grown in different directions but originated from same point. These wires are short and thick with $25 \pm 1 \mu \mathrm{m}$ and $120 \pm 2 \mathrm{~nm}$ in average length and diameter respectively. The formation of such unique morphology is not well under stood, and it will be discussed in the growth mechanism part.

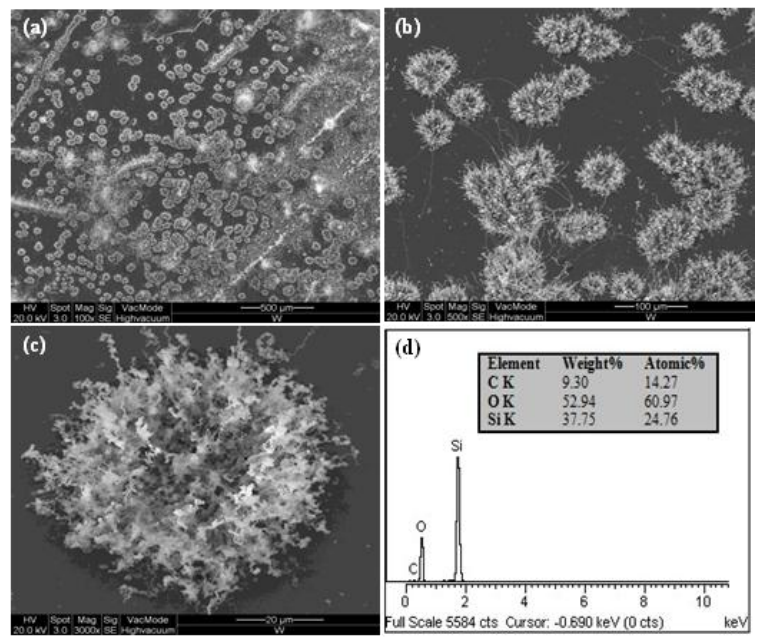

Fig. 2 - (a-c) FESEM of $\beta$-SiC bunch-like nanostructures with $0.1,0.5$ and $3 \mathrm{k}$ magnifications, respectively grown with rapid heat rate by loading the silicon substrates directly to the furnace centre with $1200^{\circ} \mathrm{C}$ at $10 \mathrm{sccm}$ of $\mathrm{Ar}$ flowrate gas for $1 \mathrm{~h}$. (d) EDX spectrum of FESEM image in Fig. 2(c)

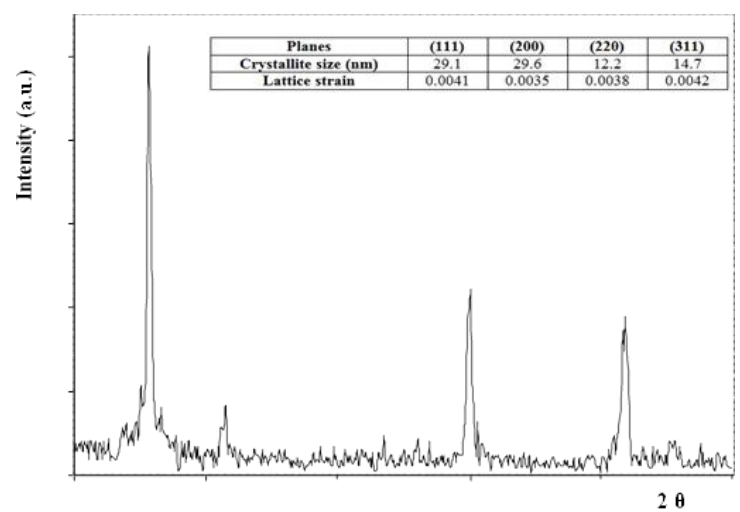

Fig. 3 - XRD patterns of $\beta$-SiC nanowires showing the crystal planes of (111), (200), (220) and (311) at $2 \theta=35.75^{\circ}, 41.5^{\circ}$, $60.1^{\circ}$ and 72.0 respectively, grown under $1200^{\circ} \mathrm{C}$ with $10 \mathrm{sccm}$ for $1 \mathrm{~h}$ and an inset table shows the crystallite size and lattice strain of the nanowires at each diffraction peak

The X-ray radiation of copper with a wavelength of $1.5418 \AA$ is utilized for crystal X-ray diffraction. The XRD spectrum shown in Fig. 3 shows four high intensity peaks, corresponding predominantly to the $\beta$-SiC nanowires zincblende unit cell crystals with planes of (111), (200), (220) and (311) at $2 \theta=35.75^{\circ}, 41.5^{\circ}, 60.1^{\circ}$ and 72.0 respectively. The first strong intensity peak of (111) followed by (220), (311) and finally there are small intense comes from (200) planes. Moreover, thinner XRD peak shows the purity of obtained crystal material with large size. The crystallite size and lattice strain can be revealed in inset table in Fig. 3. These measurements of the $\beta$-SiC nanowires with cubic struc- ture crystals were measured for four planes by using Scherrer [21] and lattice strain equations [22].

\subsection{Effect of Argon Flowrate on the Growth of Ultra-long $\beta$-SiCNWs}

The FESEM images in Fig. 4 show $\beta$-SiC nanowires synthesized at $1200{ }^{\circ} \mathrm{C}$ under different $\mathrm{Ar}$ gas flowrates and deposited for $1 \mathrm{~h}$. In this experiment the heating rate was kept unchanged at $1.2^{\circ} \mathrm{C} / \mathrm{S}$. Fig. 4(a) shows silicon wafer surface covered with long and less dense $\beta$-SiCNWs $(\approx 50 \%$ in yield). These wires were grown under $\mathrm{Ar}$ gas with flowrate of $40 \mathrm{sccm}$. While in Fig. 4(b) the synthesis process was carried under $30 \mathrm{sccm}$ flowrate and the grown $\beta$-SiCNWs seem to be denser $(\approx 70 \%$ in yield). As the flow rate decreases to 20 and $10 \mathrm{sccm}$, the resultant growth yield increases $(\approx 100 \%)$ as it revealed in Fig. 4 (c and d) respectively.
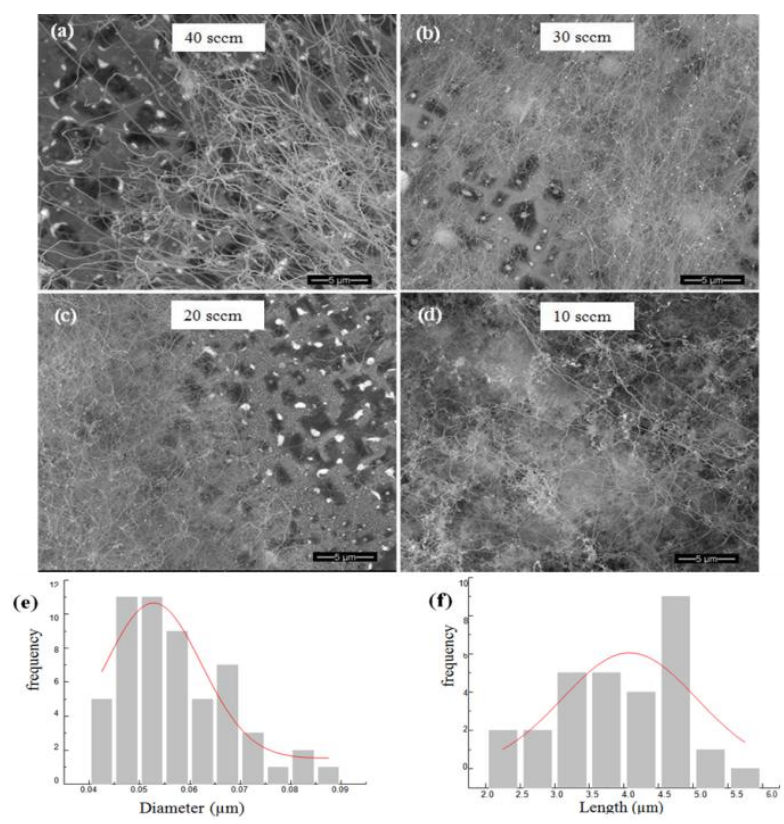

Fig. 4 - FESEM images of B-SiCNWs at (a) 40, (b) 30, (c) 20 and (d) $10 \mathrm{sccm}$ flow rates of $\mathrm{Ar}$ gas under $120{ }^{\circ} \mathrm{C}$ heating temperature for $1 \mathrm{~h}$ deposition time. (e and $\mathrm{f}$ ) the Gaussian distribution of length and diameter of obtained nanowires respectively

After scratched out $\beta$-SiCNWs from the samples surfaces of three synthetic trails, the collected $\beta$-SiCNWs powder is about $1.01 \mathrm{~g}$. This mass quantity seems to be good in nano-synthesis processes area. In Fig. 4(d) ultralong $\beta$-SiC nanowires are typically few millimeters and $57.0 \pm 3.0 \mathrm{~nm}$ in average length and diameter respectively. The $\beta$-SiC nanowires lengths and diameters distribution can be revealed in Fig. 4 (e and $\mathrm{f}$ ).

The effect of Ar gas flowrate on the growth of $\beta$-SiC nanowires can be explained as follows. There are no other sources of silicon other than the substrate itself inside the CVD system; therefore we suggest that silicon monoxide ( $\mathrm{SiO}$ ) gas will start to evaporate form the substrate surface at high temperatures $\left(950-1200{ }^{\circ} \mathrm{C}\right)$ and works as the main source of growth precursors.

The chemical reaction that produces $\mathrm{SiO}$ in gas form involves carbo-thermal reactions occurs with oxide thin layer of the silicon substrate (SiO2) [23, 24]. 
This leads to suggest that the argon gas flowrate affect the residence time of $\mathrm{SiO}$ gas over the substrate. Therefore, when the flow rate of the argon gas is high, the residence time of $\mathrm{SiO}$ gas inside the chamber is very low, which reduces the growth yield. Therefore to highlight this effect of Ar flowrate on the final results we need to generalize all growth steps starting with burning graphite at the first stage. When temperature rises gradually, the carbon monoxide $\left(\mathrm{CO}_{(\mathrm{g})}\right)$ is generated due to the oxidation of carbon as in equation (1) inside Fig. 5. At the same time and at temperatures more than $950{ }^{\circ} \mathrm{C}, \mathrm{SiO}$ vapour is produced from oxide layer as in equation (2) inside Fig. 5 . SiO vapour reacts with $\mathrm{CO}$ to form $\beta$-SiC nanowires occurring in the mole rate of $1: 1$ as in equation (3). Then to continue the growth process of $\beta$ - $\mathrm{SiC}$ nanowires more $\mathrm{CO}$ vapour is needed. Reaction (4) inside Fig. 5 recycles the process by releasing $\mathrm{CO}$ again. So $\mathrm{CO}$ plays a key role in the whole reaction process. As soon as the feedback current occurs, the $\mathrm{CO}$ vapour is synthesized continuously.

Fig. 5 shows a schematic diagram of $\beta$-SiC nanowires by oxygen assisted growth mechanism (OAG) [25], because in the free catalytic growth, the process is governed by oxygen to make the availability of growth species in gas form. When these species reach the substrate surface they react by forming nucleation seed (white dome), which was deposited on the surface due to temperature fluctuations and anchored to the silicon surface atoms as in Fig. 5(a) and with more precursors condensation, SiC nanowires start to evolve and make 1D growth, see Fig. 5(b). The length and diameter of the evolving wire depends on the availability of the growth species, which is controlled by both the heating temperature and Ar carrier gas flow-rates. At high heating rate, fast oxidation rate of carbon in the porcelain boat may reduce the $\mathrm{CO}$ gas inside the CVD chamber and hence eliminates the reaction with silicon surface as presented in equation (2) inside Fig. 5. This will form short and thicker nanowires as illustrated in Exp. 1 inside Fig. 5. In Exp. 2 inside Fig. 5(c-d), low heating rate experiment generates more $\mathrm{SiO}$ vapour at low flow-rate and hence, long $\beta$-SiC nanowires were achieved. In this experiment, some carbon powder is left on the boat, therefore, we believe that when no $\mathrm{SiO}$ gas within chamber no nanowires would evolve.

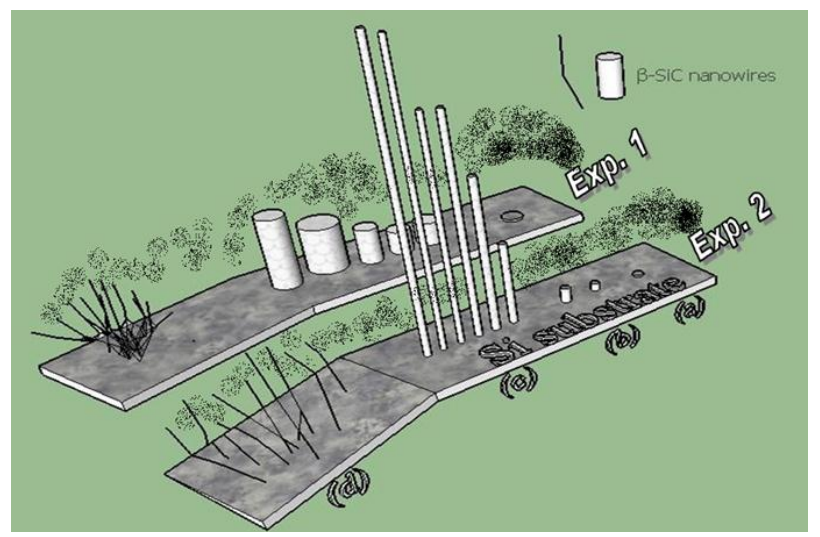

Fig. 5 - A schematic drawing of $\beta$-SiC nanowires fabrication process and the relative carbo-thermal reactions under suggested oxygen assisted growth mechanism of $\beta$-SiC nanowires
FTIR spectroscopy was utilized for more nanowires chemical composition analyzation. $\beta$-SiCNWs grown over three silicon wafers at 2,4 and $6 \mathrm{~cm}$ apart from the carbon powder were scratched and collected separately. Then, a portion of $0.1 \%$ of each sample was mixed with $\mathrm{KBr}$ and pressed into three pellets. IR measurements were performed in the range of 600 to $1000 \mathrm{~cm}^{-1}$.

FTIR spectrum in Fig. 6 represents sharp transmitted peaks of $\beta$-SiCNWs samples fabricated at 2,4 and $6 \mathrm{~cm}$ under $10 \mathrm{sccm}$ of Ar flowrate and deposited with $1200{ }^{\circ} \mathrm{C}$ for $1 \mathrm{~h}$. A transmitted peak at $798 \mathrm{~cm}^{-1}$ for sample located at $2 \mathrm{~cm}$ location indicates the transversal optic (TO) mode of Si-C stretching vibrations [26].

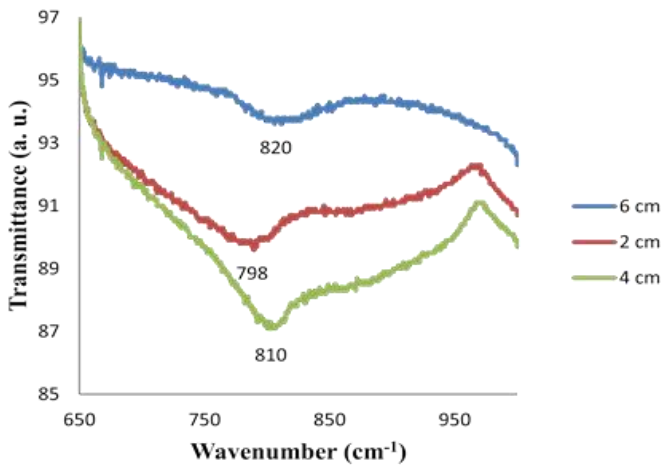

Fig. 6 - FTIR spectrum of SiC nanowires peaks corresponding to Si-C stretching vibration at 798,810 and $820 \mathrm{~cm}^{-1}$ and stretching vibration of Si-O for samples grown at 2, 4 and $6 \mathrm{~cm}$ from the furnace center respectively

Also, the other two peaks of 810 and $820 \mathrm{~cm}^{-1}$ at locations 4 and 6 centimeters are referred to the same stretching vibration mode [27]. The peak at $820 \mathrm{~cm}^{-1}$ is less intense when sample at $6 \mathrm{~cm}$, further distance, than the peaks taken from samples at 2 and $4 \mathrm{~cm}$ respectively. This indicates that tens wires can be synthesized at closer distances from the carbon powder and this is due to the existence of high concentration of $\mathrm{CO}$ and $\mathrm{CO}_{2}$ gases as explained in growth mechanism part. Also, These peaks show significant asymmetry due to the polycrystalline nature of the $\mathrm{SiC}$ nanowires.

\section{CONCLUSION}

The $\beta$-SiC nanowires were successfully fabricated using simple carbo-thermal evaporation process. High heating rate produces short and thick wires while low heating rate at $1.2{ }^{\circ} \mathrm{C} / \mathrm{S}$ produces ultra-long wires. Also, as the Ar flowrate gas inside heating chamber reduced, denser nanowires were obtained. The grown wires are poly crystalline reveals diffracted crystal planes of $\beta$-SiC (111) (200), (220) and (311). FTIR transmitted peaks at 798,810 and $820 \mathrm{~cm}^{-1}$ are referred to the transversal optic (TO) of $\mathrm{Si}-\mathrm{C}$ stretching vibration mode.

\section{AKNOWLEDGEMENTS}

Authors wish to thank Mr. Ibrahim al- Khusaibi and Saif Al-Mamari from the Central Analytical and Applied Research Unit (CAARU), college of science, Sultan Qaboos university. 


\section{REFERENCES}

1. W.P. Zheng, R.D. Zu, Z.L. Wang, Science 291, 1947 (2001).

2. Y.J. Zhang, J. Zhu, Micro 33, 523 (2002).

3. Z.L. Wang, Z.R. Dai, R.P. Gao, Z.G. Bai, J.L. Gde, Appl. Phys. Lett. 77, 3349 (2000).

4. Y.H. Gao, Y. Bando, K. Kurashima, T. Sato, J. Mater. Sci. 37, 2023 (2002).

5. Y.H. Mo, M.D. Shajahan, Y.S. Lee, Y.B. Hahn, K.S. Nahm, Synth. Met. 140, 309 (2003).

6. H.C. Lo, D. Das, J.S. Hwang, K.H. Chen, C.H. Hsn, C.F. Chen, L.C. Chen, Appl. Phys. Lett. 83, 1420 (2003).

7. C.C. Tang, S.S. Fan, H.Y. Dang, J.H. Zhao, C. Zhang, P. Li, Q. Gu, J. Cryst. Growth 210, 595 (2000).

8. Z.J. Li, H.J. Li, X.L. Chen, A.L. Meng, K.Z. Li, Y.P. Xu, L. Dai, Appl. Phys. A 76, 637 (2003).

9. M. Lu, M.K. Li, H.L. Li, X.Y. Gao, J. Mater. Sci. Lett. 22, 1107 (2003).

10. W. Yang, H. Araki, A. Kohyama, S. Thaveethavorn, H. Suzuki, T. Noda, Mater. Lett. 58, 3145 (2004).

11. A.I. Kharlamov, N.V. Kirillova, S.N. Kaverina, Theor. Exp. Chem. 38, 237 (2002).

12. Z.X. Yang, Y.J. Wu, F. Zhu, Y.F. Zhang, Physica E 25, 395 (2005).

13. W.Y. Yang, H.Z. Miao, Z.P. Xie, L.G. Zhang, L.N. An, Chem. Phys. Lett. 383, 441 (2004).

14. W.S. Shi, Y.F. Zhang, H.Y. Peng, N. Wang, C.S. Lee, S.T. Lee, J. Am. Ceram. Soc. 83, 3228 (2000).
15. Y.B. Li, S.S. Xie, X.P. Zou, D.S. Tang, Z.Q. Liu, W.Y. Zhou, G. Wang, J. Cryst. Growth. 223, 125 (2001).

16. G. Attolini, F. Rossi, F. Fabbri, M. Bosi, B.E. Watts, G. Salviati, Mater. Lett. 63, 2581 (2009).

17. L.Z. Cao, H. Jiang, H. Song, Z.M. Li, X. Liu, W.G. Guo, D.W. Yan, X.J. Sun, H.F. Zhao, G.Q. Miao, D.B. Li, J. Nanosci. Nanotechnol. 10, 2104 (2010).

18. J. Wei, K. Li, J. Chen, H. Yuan, J. Cryst. Growth 335, 160 (2011).

19. Z. Li, X. Liu, M. Zhang, M. Zhai, Computational Mater. Sci. 96, 63 (2015).

20. Majid S. Al-Ruqeishi, Roslan Md Nor, Yusoff Mohd Amin, Khalifa Al-Azri, J. Alloy. Compd. 497, 272 (2010).

21. P. Scherrer, Göttinger Nachrichten Gesell 2, 98 (1918).

22. Masaki Amaya, Jinichi Nakamura, Toyoshi Fuketa, J. Nuclear Sci. Technol. 45, 244 (2008).

23. Gundiah, F.L. Deepak, A. Govindaraj, C.N.R. Rao, Chem. Phys. Lett. 381, 579 (2003).

24. H. Liu, Z. Huang, M. Fang, Y. Liu, X. Wu, J. Crystal Growth 419, 20 (2015).

25. J. Zhu, X. Xiong, H.T. Chen, X.L. Wu, W.C. Zhang, Chu, K. Paul, J. Nanosci. Nanotechnol. 9 No 11, 6648 (2009).

26. N. Keller, C. Pham-Huu, S. Roy, M.J. Ledoux, C. Estournes, J. Guille, J. Mater. Sci. 34, 13 (1999).

27. K. Okada, H. Kato, K. Nakajima, J. Am. Ceram. Soc. 77, 6 (1994). 